\title{
What Enables Self-Control? A Test of Glucose, Fructose, and Vagus Nerve Activation as Possible Factors
}

\section{¿Que permite el autocontrol? Un test de glucosa, fructosa y activación del nervio vago como posibles factores}

\author{
Elizabeth D. Clohecy, Lionel G. Standing and Stuart J. McKelvie \\ Department of Psychology, Bishop's University, Canada
}

Disponible online 30 de abril de 2015

\begin{abstract}
This study replicated the study by Miller, Bourrasseau, and Blampain (2013) on the effects of fructose and glucose on self-control. It also investigated these authors' suggestion that self-control may be under the influence of the vagus nerve, which can be activated by forceful exhalation in the Valsalva manoeuvre. The participants $(N=101)$ were assigned to one of five conditions: three groups that received a solution of either glucose, fructose, or a placebo sweetener (solution condition); and two groups that underwent the Valsalva manoeuvre (VM and VM-control). Participants in the solution condition groups ingested one of the three sweeteners, whereas those in the VM and VM-control conditions were required to blow or not blow into a manometer for 15 seconds, respectively. The number of anagrams that participants subsequently completed was used to assess their level of self-control. In contrast to the results obtained by Miller et al. (2013), it was found that fructose, glucose, and VM did not increase the participants' levels of self-control compared to control subjects. These negative results concur with several recent studies which document the difficulty of replicating published findings in psychology.
\end{abstract}

Key words: Fructose; Glucose; Self-control; Vagus Nerve.

\begin{abstract}
Este estudio es una réplica del estudio realizado por Miller, Bourrasseau y Blampain (2013) sobre los efectos de la fructosa y la glucosa en el autocontrol. También se contrastó la sugerencia de estos autores de que el autocontrol puede estar bajo la influencia del nervio vago, que puede ser activado mediante una exhalación enérgica mediante la maniobra de Valsalva. Los participantes ( $\mathrm{N}=101)$ fueron asignados a una de las cinco condiciones: tres grupos que recibieron una solución (glucosa, fructosa o un edulcorante placebo) y dos condiciones que ejecutaban la maniobra de Valsalva (MV, y MV-control). Los participantes de la condición de "solución" ingirieron uno de los tres edulcorantes, mientras que los participantes de la condición MV y MV-control, se les pidió que soplasen/no soplasen dentro de un manómetro durante 15 segundos, respectivamente. El número de anagramas que los participantes completaron posteriormente se utilizó para evaluar su nivel de autocontrol. Contrariamente a los resultados de Miller et al. (2013), ni la fructosa ni la glucosa aumentaron los niveles de autocontrol de los participantes en comparación con los sujetos control, ni MV afectó al autocontrol. Estos resultados negativos coinciden con varios estudios recientes que documentan la dificultad de replicar los hallazgos publicados en la psicología.
\end{abstract}

Palabras clave: Fructosa; Glucosa; Autocontrol; Nervio Vago.

Correspondence concerning this article should be addressed to Elizabeth D. Clohecy, Department of Psychology, Bishop's University, Sherbrooke QC, Canada J1M 1Z7. Email: eclohecy11@ubishops.ca. Co-authors’ e-mails: Lionel G. Standing, 1standin@ubishops.ca, Stuart J. McKelvie: smckelvi@ubishops.ca.

This paper is based on a Psychology Honours dissertation prepared by the first author, supervised by the second and third authors. The support of the Bishop's University Research Committee is gratefully acknowledged. 
For many people, following a diet appears to be psychologically exhausting. Baumeister, Bratslavsky, Muraven \& Tice (1998) offer an explanation for this, in suggesting that the continued activation of behaviors that require a large amount of self-control will soon lead to its depletion. Self-control, or selfregulation, is important in that it implies the ability to overcome one's short-term desires in order to achieve longer-term goals. Consequently those people who have habitual high levels of self-control show enhanced success in their personal and academic lives (Tangney, Baumeister \& Boone, 2004).

Subsequently this 'strength' theory of self-control was extended when it was argued that the brain's requirements for glucose are high (Gailliot, 2008) and that as self-control depends on it as an energy source, it will be sensitive to changes in brain glucose levels (Galliot, Baumeister, DeWall, Maner, Plant, Tice \& Brewer, 2007). In a series of experiments employing various tasks these latter authors found as predicted that selfcontrol was raised by the ingestion of a glucose solution (Studies 7, 8 and 9). In accordance with this idea, Fairclough and Houston (2004) found that increased attentional effort in the Stroop task for perceptual-interference can deplete blood glucose. However, controversy arose when Carter, Jeukendrup and Jones (2004) observed that the same effects could be obtained merely by rinsing participants' mouths with a carbohydrate solution. Then, using neural imaging studies, Chambers, Bridge and Jones (2009) suggested an alternative 'motivational' explanation for the later findings, arguing that when carbohydrates are sensed in the mouth, reward and motor control areas in the brain are activated that can cause an increase in self-control during athletic activities. This idea is based on the findings of O'Doherty, Rolls, Francis, Bowtell and McGlone (2001) that oral glucose activates the primary and secondary cortical regions for taste, regions that project to the reward areas of the brain (Rolls, 2007).

Another problematic issue is that while Galliot et al. (2007) reported that their experiments 1 and 2 altered participants' level of blood glucose, Kurzban (2010) had rejected this claim, arguing that it was based on inadequately standardized measures of blood glucose levels. Molden et al. (2012), using a more precise measure of blood glucose than that of Galliot et al. (2007), found that although rinsing with a carbohydrate solution did not increase blood glucose levels, it improved the subject's self-control, a result which supports the motivational model of self-control.

Much debate has arisen concerning these competing explanations, in which perhaps the most controversial findings are those of Miller et al. (2013), who found that the same boost in self-control occurred with a fructose solution as with glucose, a seemingly straightforward result. However, fructose is not metabolized in the same manner as glucose, and cannot activate the same reward and motor control areas of the brain. The results suggest that both previously proposed explanations may be incorrect in their identification of the mechanisms that promote self-control.

Miller et al. (2013) therefore suggest an alternative hypothesis to account for their results, proposing instead that the enhanced self-control caused by ingestion of glucose and fructose is due, at least in part, to activation of the vagus nerve. Previous research has found that the presence of carbohydrates in the oral cavity can cause this reaction, since Brown, Dulloo, Yepuri, and Montani (2008) found that fructose and glucose intake significantly increased blood pressure variability and decreased cardiovagal baroreflex sensitivity, both indicating stimulation of the vagus nerve, whereas this did not occur after ingestion of water.

Therefore, in an attempt to resolve the issue, the present study aimed both to replicate the findings by Miller et al. (2013), and also to test their hypothesis that activation of the vagus nerve may be a mechanism involved in self-control.

To address these aims five independent treatments were used in the present study. Three conditions required participants to ingest a glucose, fructose, or placebo solution. The other two conditions assigned participants to perform either the Valsalva maneuver (VM) to stimulate vagal tone, or a VM-control task. Following the original study by Miller et al. (2013), the dependent measure (the subject's level of self-control) was assessed as the number of anagrams that were completed by the participants after each treatment. This task involves sustained effortful attention, and thus requires the subject to exert self-control.

Based on the findings of Miller et al. (2013), we predicted that the participants who had ingested fructose or glucose solutions would solve significantly more anagrams than participants who had consumed a placebo solution. We also hypothesized that the participants who had performed the VM would solve significantly more anagrams than those in the VM-control condition. In addition, we hypothesized that the participants in the glucose, fructose and VM conditions would solve a comparable number of anagrams.

The current work also employed a series of self-report measures, to control for extraneous variables and serve as manipulation checks. According to Self-Determination Theory (SDT), a setting which supports an individual's experience of autonomy, competence, and relatedness will foster motivation that will increase task engagement and enhance performance (Deci \& Ryan, 2000). Therefore, we assessed the subjects' basic need satisfaction and general motivation prior to the completion of the experimental task, and after its completion assessed affect and situational motivation. We predicted that participants who reported high basic psychological need satisfaction, were highly motivated, and reported positive affect would complete more anagrams. We also determined the participants' levels of vitality and feelings of being drained, both prior to the completion of the self-control task and after its completion. On the post- 
test, it was predicted that participants in the glucose, fructose, and VM conditions would report a lower feeling of drain, and higher feeling of vitality, than participants in the placebo and VM-control groups.

\section{Method}

\section{Participants}

The study involved 101 undergraduate student volunteers between the ages of 18 and 45, at Bishop's University $\left(M_{\text {age }}=\right.$ 21.03 years, $S D=2.98$ ). There were 20 participants in each of the conditions except for the VM-control condition, which contained 21 participants. Of the participants, $67 \%$ were female, with $81 \%$ reporting their first language as English. Participants with heart conditions were excluded from the study, due to the possible risk associated with the fluctuation in heart rate caused by the Valsalva maneuver.

\section{Materials}

The questionnaire consisted of two sections. There was a slight variation in Part 1, as participants in the solutions conditions were given two additional questions on a five-point scale designed by the first author to determine if they preferred one solution over another: "I felt that the drink was enjoyable", and "I would drink the drink again if given an opportunity". Part 1 also contained demographic questions: "What is your age (in years)?", "What is your gender (male, female, or other)?", and "Is English your first language (yes/no)?" The remaining sections of Part 1 consisted of three questionnaires: the Basic Need Satisfaction Scale (BNS) (Gagne, 2003), the General Motivation Scale (GMS) (Pelletier et al., 2005) and a version of the Positive and Negative Affects Scale (PNAS) (Watson, Clark \& Tellegen, 1988).

Part 2 of the questionnaire began with three questions concerning participants' performance on the self-control task: (1) How many minutes do you think you spent during the entire task? (2) How many anagrams did you try to solve? (3) How many anagrams were you able to solve?) (These data are not reported here). The remaining sections of Part 2 consisted of two questionnaires, the Subjective Vitality Scale (SVS) (Ryan \& Frederick, 1997), and the Situational Motivational Scale (SIMS) (Guay, Vallerand \& Blanchard, 2000).

The solutions contained $300 \mathrm{~mL}$ of water infused with lemon juice as a base, and either $25 \mathrm{~g}$ of fructose, $25 \mathrm{~g}$ of glucose, or a matched amount of Splenda as a non-carbohydrate placebo. A sphygmomanometer (a small gauge held in the mouth) was used to ensure that participants maintained a specified pressure while they were engaging in the VM.

A list of 25 anagrams of words randomly selected from the dictionary of (4-8) letters was used; the subject's persistence in this task was taken as a measure of their self-control.

\section{Design}

The study used a one-way independent groups ANOVA design, with subjects randomly assigned to one of five conditions: glucose, fructose, Splenda, VM, or VM- control. Each group was also matched on gender and language. The dependent variable was the number of anagrams that the participant solved. The block diagram of the procedural steps is shown in Figure 1.

Figure 1

Procedural steps.

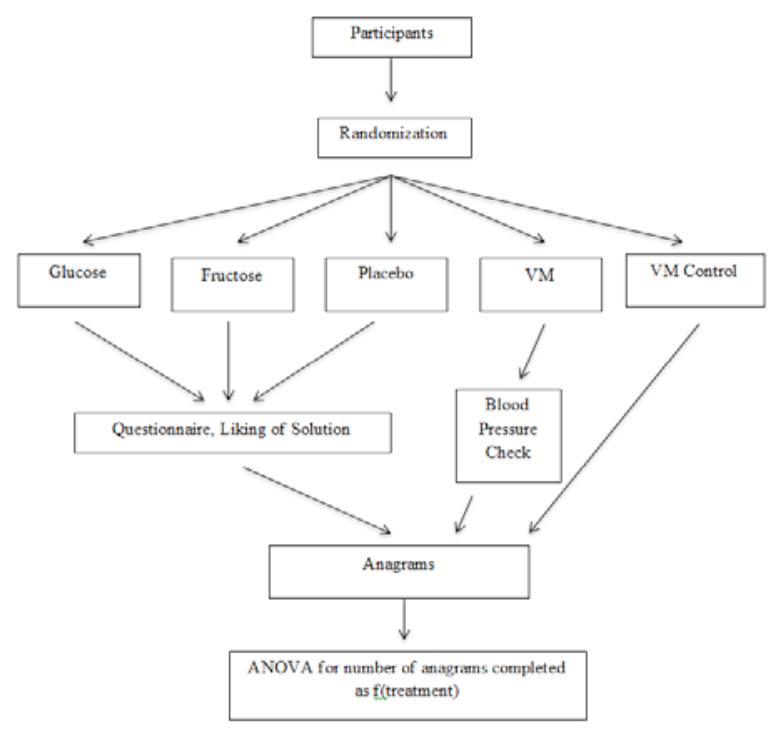

\section{Procedure}

All participants gave their informed consent to take part in the study, following the protocol of the Bishop's University Research Ethics Board. They were required to refrain from eating for three hours prior to the study, although drinking water was permitted. To begin, all participants completed Part 1 of the questionnaire. The next step depended on their assigned condition. Participants in the VM groups were instructed to take a deep breath and either blow into a manometer for 15 seconds while maintaining a pressure of $40 \mathrm{~mm} \mathrm{Hg}$, or not to blow into it. Participants in the solution conditions drank one of the three solutions over a period of $10 \mathrm{~min}$. The participants were then instructed to try to complete the 25 anagrams in writing, in the order in which they were presented, continuing for 20 minutes or until they felt they were unable to do any more. Once they had finished with the anagram task participants filled in Part 2 of the questionnaire.

\section{Results}

\section{Descriptive Statistics for Anagram Completion}

Participants completed on average 12.18 of the 25 anagrams overall $(S D=3.75)$. The mean numbers of completed 
anagrams for the five conditions were: Glucose $(M=12.15, S D$ $=4.40)$, Fructose $(M=12.35, S D=5.02)$, Placebo $(M=11.95$, $S D=3.17), \mathrm{VM}(M=13.10, S D=3.24)$, and VM-Control $(M=$ $11.38, S D=2.64)($ See Figure 2).

\section{Figure 2}

Mean number of anagrams completed as a function of condition. (VM = Valsalva Maneuver). Error bars show SEMs.

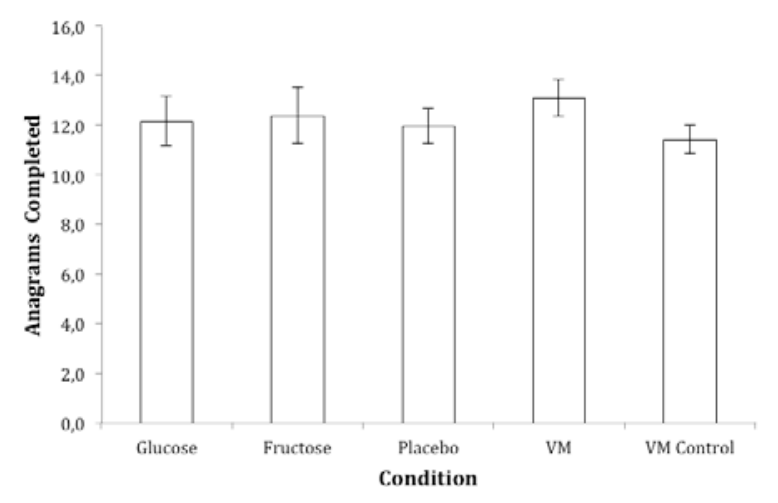

\section{ANOVA on Number of Anagrams Completed}

A one-way ANOVA conducted on the anagram scores showed no difference between the five conditions (glucose, fructose, placebo, VM, and VM-control), $F(4,96)=0.56, p=$ 0.69 , partial $\eta 2=0.02$ (See Figure 2). Although the VM-Control appears slightly lower than the other four conditions, this difference was not reliable, $t(99)=1.09, p=.28$. Nor was a there a significant difference between the lowest and the highest conditions (VM and VM-control), $t(39)=1.87, p=.069,95 \%$ CIs $[-.72,4.3]$.

ANOVA on Solution Type and Questionnaire Scores (Preference for Solution)

The type of solution (glucose, fructose, or placebo) did not influence participants' responses on the Preference for Solution Questionnaire for question 1 (enjoyability of the drink), $F$ (2, 57 ) $=1.06, p=0.35$, partial $\eta 2=0.04$, nor for question 2 (willingness to drink it again), $F(2,57)=3.49, p=0.63, \eta 2=0.11$.

\section{ANOVA for the BNS, GMS, and Positive \& Negative Affect (Part 1)}

The participants' basic need satisfaction did not differ significantly between conditions, $F(4,96)=0.98, p=0.42, \eta 2$ $=0.04$, nor did their general motivation, $F(4,96)=0.35, p=$ $0.84, \eta 2=0.02$. Their negative and positive affect also did not differ between conditions, $F(4,96)=0.26, p=0.91, \eta 2=0.01$, and $F(4,96)=0.30, p=0.88, \eta 2=0.01$, respectively.

\section{ANOVA for the SVS and SIMS (Part 2)}

After completing the anagrams, participants' level of vitality and drain did not differ significantly over conditions, $F$ (4,
96) $=1.14, p=0.35, \eta 2=0.05$, and $F(4,96)=2.19, p=0.08$, $\eta 2=0.08$, respectively. Nor were their levels of situational motivation affected, $F(4,96)=0.97, p=0.43, \eta 2=0.04$.

\section{Discussion}

The results were expected to support the findings of Miller et al. (2013). However, although the mean scores in the glucose, fructose, and VM conditions fell in the expected direction when compared to the controls, the differences were very small. Consuming glucose or fructose did not significantly increase participants' performance on the self-control task, nor was performance enhanced by stimulation of the vagus nerve using the Valsalva maneuver.

The present study also employed manipulation checks through self-report measures and again, contrary to original predictions, there were no significant differences between the conditions for feeling of vitality or drain after completion of the anagrams, further suggesting that the glucose, fructose, and VM conditions all failed to produce an increase in self-control.

In addition, the current work also assessed motivation, affect and preference towards the solutions prior to performing the anagrams task, as possible confounding variables, the results for the BNS, GSD, and PNAS measures indicating that no significant differences in motivation and mood existed across the conditions before performing the self-control task. After completing it, situational motivation was assessed and once more showed no differences across conditions. No preferences were shown towards a specific type of solution.

No obvious differences in methodology suggest why these results differ from those of Miller et al. (2013). However, some limitations in the current work may have contributed to the failure to find any effect of the treatments. The required fasting period might have been longer, and behaviours known to influence heart rate (e.g., smoking, and/or exercise) could have been excluded. Ideally, both pre- and post-treatment mood testing with all tests would have been performed. External validity is limited, in that all subjects came from Bishop's University, a demographic of students typically from 18 to 25 years of age, and including more females than males. On the other hand, gender and language were matched across conditions. Moreover, the statistical power of the study appears adequate, since it used a cell size of 20/21, and Miller et al. (2013) estimate that a cell size of 12 should produce a power of .90 for detecting the effect of glucose on self-control, with a similar figure for fructose.

The present results indicate that the reported enhancement of self-control previously found when using glucose or fructose may not be a replicable finding. There has been extensive research on why we fail to exert self-control, and results indicate consistently that possessing a higher habitual degree of self-control will lead to a much happier, healthier, and more successful individual (Tangney, Baumeister \& Boone, 2004). Therefore, it is important that this research continue, in the hope of finding practical measures to increase self-control as 
applied to, e.g., eating or drinking behaviour. The contradictory results obtained here suggest the need for further studies, particularly in light of the recent realization that many major findings reported in the peer-reviewed literature in various areas of psychology cannot be replicated by independent investigators (Bonett, 2012; Schmidt, 2009). It is hoped that replication/extension studies such as the present one may help to buttress psychological knowledge more securely, as well as offering some pedagogical opportunities (Standing, Grenier, Lane, Roberts, \& Sykes, 2014).

\section{References}

1. Baumeister, R. F., Bratslavsky, E., Muraven, M. \& Tice, D. M. (1998). Ego depletion: Is the active self a limited resource? Journal of Personality and Social Psychology, 74, 1252-1265. http://dx.doi.org/10.1037/0022$\underline{3514.74 .5 .1252}$

2. Bonett, D. G. (2012). Replication-extension studies. Current Directions in Psychological Science, 21, 409-412. http://dx.doi.org/10.1177/0963721412459512

3. Brown, C. M., Dulloo, A. G., Yepuri, G. \& Montani, J. P. (2008). Fructose ingestion acutely elevates blood pressure in healthy young humans. American Journal Physiology Regulatory Integrative Comparative Physiology, 294, 730-737. http://dx.doi.org/10.1152/ajpregu.00680.2007

4. Carter, J. M., Jeukendrup, A. E. \& Jones, D. A. (2004). The effect of carbohydrate mouth rinse on 1-h cycle time trial performance. Medicine and Science in Sports and Exercise, 36, 2107 - 2111. http://dx.doi.org/10.1249/01. MSS.0000147585.65709.6F

5. Chambers, E. S., Bridge, M. W. \& Jones, D, A. (2009). Carbohydrates sensing in the human mouth: effects on exercise performance and brain activity. Journal of Physiology, 587, 1779-1794. http://dx.doi.org/10.1113/jphysiol.2008.164285

6. Deci, E. L. \& Ryan, R. M. (2000). The "what" and "why" of goal pursuits: Human needs and the self-determination of behavior. Psychological Inquiry, 11, 227-268. http://dx.doi. org/10.1207/S15327965PLI1104_01

7. Fairclough, S. H. \& Houston, K. (2004). A metabolic measure of mental effort. Biological Psychology, 66, 177-190. http://dx.doi.org/10.1016/j.biopsycho.2003.10.001

8. Gagne, M. (2003). The role of autonomy support and autonomy orientation in prosocial behavior engagement. Motivation and Emotion, 27, 199-223. Retrieved from http://www.selfdeterminationtheory.org/questionnaires/10questionnaires/53. http://dx.doi.org/10.1023/A:102500761 $\underline{4869}$

9. Gailliot, M. T. (2008). Unlocking the energy dynamics of executive functioning: Linking executive functioning to brain glycogen. Perspectives on Psychological Science, 3, 245263. http://dx.doi.org/10.1111/j.1745-6924.2008.00077.x

10. Galliot, M. T., Baumeister, R. F., DeWall, N. C., Maner,
J. K., Plant, A. E., Tice, D. M. \& Brewer, L. E. (2007). Self-control relies on glucose as a limited energy Source: Willpower is more than a metaphor. Journal of Personality and Social Psychology, 92, 325-336. http://dx.doi. org/10.1037/0022-3514.92.2.325

11. Guay, F., Vallerand, R. J. \& Blanchard, C. (2000). On the assessment of situational intrinsic and extrinsic motivation: The Situational Motivation Scale (SIMS). Motivation and Emotion, 24, 175-213. http://dx.doi. org/10.1023/A:1005614228250

12. Kurzban, R. (2010). Does the brain consume additional glucose during self-control tasks? Evolutionary Psychology, 8, 244-259.

13. Miller, H. C., Bourrasseau, C. \& Blampain, J. (2013). Can you enhance executive control without glucose? The effects of fructose on problem solving. Journal of Psychopharmacology, 27, 645-650. http://dx.doi. org/10.1177/0269881112473790

14. Molden, D. C., Hui, C. M., Scholer, A. A., Meier, B. P., Noreen, E. E., D’Agostino, P. R. \& Martin, V. (2012). Motivational versus metabolic effects of carbohydrates on self-control. Psychological Science, 23, 1137-1144. http:// dx.doi.org/10.1177/0956797612439069

15. O’Doherty, J., Rolls, E. T., Francis, S., Bowtell, R. \& McGlone, F. (2001). Representation of pleasant and aversive taste in the human brain. Journal of Neurophysiology, 85, 1315-1321.

16. Pelletier, L. G., Blanchard, C. M., Sharp, E. C., Otis, N., Vallerand, R. J. \& Guay, F. (2005). The General Motivation Scale: A dispositional measure of intrinsic, extrinsic, and amotivation for different life activities. Manuscript in preparation, University of Ottawa.

17. Rolls, E. T. (2007). Sensory processing in the brain related to the control of food intake. Proceedings of the Nutrition Society, 66, 96-112. http://dx.doi.org/10.1017/ $\underline{\text { S0029665107005332 }}$

18. Ryan, R. M. \& Frederick, C. M. (1997). On energy, personality and health: Subjective vitality as a dynamic reflection of well-being. Journal of Personality, 65, 529-565. http:// dx.doi.org/10.1111/j.1467-6494.1997.tb00326.x

19. Schmidt, S. (2009). Shall we really do it again? The powerful concept of replication is neglected in the social sciences. Review of General Psychology, 13, 90-100. http://dx.doi. org/10.1037/a0015108

20. Standing, L. G., Grenier, M., Lane, E. A., Roberts, M. S., \& Sykes, S. J. (2014). Using replication projects in teaching research methods. Psychology Teaching Review, 20, 94-102.

21. Tangney, J. P., Baumeister, R. F. \& Boone, A. L. (2004). High self-control predicts good adjustment, less pathology, better grades, and interpersonal success. Journal of Personality, 72, 271-324. http://dx.doi.org/10.1111/j.0022$\underline{3506.2004 .00263 . x}$ 
22. Watson, D., Clark, L. A. \& Tellegen, A. (1988). Development and validation of brief measures of positive and negative affect: The PANAS scales. Journal of Personality and Social Psychology, 54, 1063-1070. http://dx.doi. org/10.1037/0022-3514.54.6.1063

Received 8 September 2014

Received in revised form 24 November 2014

Accepted 15 December 2014 